\title{
The Use and Impact of Manufacturing Productivity Improvement Tools and Methodologies within the Automotive Component Industry
}

\author{
Robert Trimble $^{1}$, Keith Copeland ${ }^{1}$, John MacIntyre ${ }^{1} \&$ Peter Smith $^{1}$ \\ ${ }^{1}$ Faculty of Applied Sciences, University of Sunderland, Sunderland, UK \\ Correspondence: Robert Trimble, Faculty of Applied Sciences, University of Sunderland, Sunderland SR6 0DD, \\ UK. Tel: 44-191-515-3859. E-mail: rob.trimble@sunderland.ac.uk
}

Received: November 24, 2012 Accepted: January 18, 2013 Online Published: March 4, 2013

doi:10.5539/emr.v2n1p21 URL: http://dx.doi.org/10.5539/emr.v2n1p21

\begin{abstract}
This paper presents the results of a study which was undertaken with the overarching objective of investigating the use and impact of manufacturing productivity improvement approaches within automotive component suppliers. It has the specific aims of identifying (i) the level of understanding and use of continuous improvement tools and management methodologies within organisations and (ii) the factors which could contribute to them failing to achieve the results expected. The results of a survey of 161 automotive suppliers are presented. The survey investigated all elements of selection, training and implementation of tools and methodologies. This paper highlights that the adoption of continuous improvement tools and methodologies is widespread and discusses the relatively high failure rates. The reasons which may contribute to failure are presented and discussed, with the major findings being a lack of suitable resources, a lack of understanding and training within senior personnel and a non-strategic approach to the application of tools and methodologies.
\end{abstract}

Keywords: automotive component suppliers, productivity improvement tools

\section{Introduction}

The UK has for many years had a strong automotive industry both in vehicle manufacture and component supply. The Society of Motor Manufactures and Traders (SMMT) have outlined that the UK's relatively low business costs made it one of the most attractive locations for investment within developed economies (SMMT, 2004). The automotive supply chain is important to the UK economy and in 2010 there were 2350 companies who regarded themselves as automotive suppliers who provided 82,000 jobs and generated $£ 4.5$ - $£ 5$ billion of added value (SMMT, 2012). The automotive supply industry like the automotive manufacturing industry is highly competitive with ever increasing competitive pressure. The demand from vehicle manufacturers for increased competitiveness has resulted in the need for business improvement in all aspects of the supplier base. Terms such as 'Lean' and 'Continuous Improvement' are now used in all areas of business as companies try to find areas for improvement. The automotive component supply and automotive manufacturing industry is seeing continuous changes with greater emphasis being placed on areas such as modular manufacturing, flexible manufacturing systems, digital trials and outsourcing. The introduction of these changes along with a greater focus on cost reduction, quality and productivity improvement has created the situation where a myriad of continuous improvement tools and management methodologies are now being used within automotive suppliers to help achieve the improvements they require. This research had the overarching objective of investigating how useful these approaches to improving business performance are with the specific aims of identifying (i) the level of understanding and use of continuous improvement tools and management methodologies within organisations and (ii) the factors which contribute to them failing to achieve the results expected. The remainder of the paper is structured as follows: Section 2 - contains a literature review defining continuous improvement tools and management methodologies and outlines the issues contributing to their implementation failure; Section 3 describes the methodology utilised in this research; Section 4 - contains the results of the research and Section 5 - discusses the results and indicates that a new framework is required to improve implementation success.

\section{Literature Review}

Continuous improvement tools can be defined as tools that are 'stand-alone' and which can be used to resolve particular problems or make improvements in certain focused areas. In addition, they have a clear role and are narrow in focus. There are numerous continuous improvement tools examples include, Failure Mode Effect 
Analysis (FMEA), 5s and Value Stream Mapping. Individual continuous improvement tools do not need any other tools or methodologies to be able function and come in many forms ranging from very simplistic to complex. As they tend to be only used in certain areas of the company, they do not normally require significant resources or investment other than initial training and implementation. Dale and McQuater (1998) draw distinction between a tool (what we have termed a continuous improvement tool) and a technique (what we have termed a management methodology). A tool is a simple standalone application; whereas a technique tends to be a more comprehensively integrated approach to problem solving that might rely on a number of supporting tools.

Bamford and Greatbanks (2005) and McQuater, Scurr, Dale \& Hillman (1995) refer to management methodologies as 'techniques' and describe them as wider applications often resulting in the need for more thought, skill and training to be used effectively. Management methodologies are sometimes referred to as 'radical' improvement programmes (Michela, Jha \& Noori, 1996) and are best described as being the whole 'tool kit' with the tools inside the 'integrated tool kit' being a specific set of continuous improvement tools. Management methodologies are the 'road map' or 'project plans' that give a step by step systematic approach to problem solving. Management methodologies are normally adopted across many facets of the organisation and often need substantial resources and budgets for training, implementation and sustainability. Examples of management methodologies are Total Quality Management (TQM), Business Process Reengineering (BPR), Six Sigma $(6 \sigma)$ and Objective Policy Deployment (OPD). A global manufacturing industry benchmark survey conducted by Deloitte Touche Tohmatsu (2004) found that the companies connected with the automotive industry have adopted management methodologies in greater numbers than general manufacturing companies. Bunney and Dale (1997) found that the use of particular tools or techniques is related to the stages of development of the organisations improvement process.

The selection of the correct tool or management methodology is key to any continuous improvement intervention programme. Pavnaskar, Gershenonson, \& Jambekar (2003) suggest there is a plethora of different tools and methodologies developed for different purposes whilst Bhuiyan and Baghel (2005) comment: "To the author's knowledge little focus has been directed towards developing a framework or model that would enable an organisation to identify the continuous improvement methodology that best suits its needs". Pavnaskar et al (2003) have also highlighted that there have been many misapplications of lean tools and suggests that these fall in to three categories: the use of wrong tool to solve problems; the use of a single tool to solve all problems and the use of the same set of tools on all problems.

Herron and Braiden (2004) observed 43 manufacturing companies and highlighted similar issues to those outlined by Pavnaskar et al (2003). They have added to this list stating that through their observations there is a fourth point which is a lack of understanding of the tools. Grunberg (2007) states that just as there are often different sources of a problem, there are also different opinions regarding the most appropriate improvement tool to use. The selection of tools and methodologies together with their implementation is a major problem for many companies (Wickens, 1998; Grunberg, 2003).

Although much work has been done to deploy management methodologies and tools, the literature suggests that project failure continues to be an issue. Published figures generally show a high percentage failure rate (Chang 1995; Hurst 2005). Published success rates vary but there are examples of success rates of below $50 \%$ or even as low as $20 \%$ (Strebel, 1996).

Goldenson and Herbsleb (1995) undertook a survey of 138 organisations which showed that nothing had changed in $26 \%$ of companies following continuous improvement efforts, $49 \%$ of companies reported disillusionment over the lack of improvement, $72 \%$ of process improvement initiatives had suffered due to time and resource limitations, $68 \%$ stated the cost of the improvement was more than expected, and $67 \%$ believed they needed more guidance about exactly how to implement successful process improvement programs.

Although continuous improvement tools and management methodologies are said to be generic and can be applied to any process and any industry (Weller, 2000; Bamford \& Greatbanks, 2005), the implementation period and the period of time required for the tools or methodologies to become embedded within the company may be a function of the nature of the industry. There would appear to be limited evidence within the literature to suggest that any specific tool or methodology was more prone to failure. Indeed, the reasons for failure are many, and can be broadly categorised as below:

- Lack of resources

- People and cultural issues

- Poor implementation and planning 
- Poor management commitment

- Poor tool and project selection

- Poor communication

- Lack of training

Each of these is discussed below.

Lack of resources: Many improvement activities are initiated to reduce costs and improve productivity. Organisations do this because they are already over committed on headcount and budget, and costs are often spiralling out of control. It is very hard for these companies to release staff from core activities to allow them to participate in improvement projects and there is little cash available to pay for consultants and training. However many realise that they need to improve their performance so valuable resources have to be given up if any improvements are to be made. Failure is found in organisations who try to cut corners on resources only to find that it costs them valuable time and money, and employee moral decreases leading to even more resistance to future initiatives (Perry, 1995; Cooke \& Dale, 1995).

People and cultural issues: Bessant, Caffyn, Gilbert, Harding \& Webb, (1994) believed that the factors which could inhibit the momentum for continuous improvement included a lack of commitment, and cultural issues. There was also evidence that companies look for what they termed the 'big bang' innovation whilst undervaluing incremental changes. Yeh (2003) discusses how a successful management methodology such as TQM requires employees' engagement in extra-role behaviours. Yeh's study identified critical factors that may enhance or hinder employees' participation in management methodologies. Pavnaskar et al (2003), Herron (2006) and Aubrey (2001) discuss success and failure of change interventions and the reasons why some organisations are successful whilst others using the same tools or methodologies had abject failure.

Poor implementation and planning: Management methodologies may be applied to existing problems rather than using them to analyse critical business processes and develop alternative business methods. In such cases implementation may be swift but incorrectly focused on non-critical performance measures of the organisation resulting in less impact on the business. Management methodologies may best be suited for use in companies in a dynamic environment, or ones needing to undergo radical change, these may be companies who are wholly inefficient or have been stagnant in their development for many years (Dillard, Ruchala \& Yuthas 2005). Where companies have previously implemented management methodologies their successful or failed implementation can affect employee attitudes to any new methodology. The success of past change efforts, the current degree of employee involvement and trust, and top management's enthusiasm are all factors that may be involved in choosing management methodologies and how they are implemented (Dillard et al, 2005). A poor understanding of these situations may lead organisations to choose a management methodology which its culture is not suited to and which could therefore lead to the failure of the implementation.

Poor management commitment: For continuous improvement to be successful there has to be a supportive organisational structure with clear management commitment (Kotter, 1995; Herron, 2006). Senior management often agree to support improvement initiatives without completely realising the investment required (Stelzer and Mellis, 1998) which may be due to their lack of understanding of the continuous improvement tools. Emiliani and Stec (2005) found that where a continuous improvement transformation had been the most successful there was long term sustainability in senior management commitment. A lack of senior management vision in terms of the end objectives sought, lack of support by the leaders and the inability to introduce and make change happen will result in almost certain failure (Herron, 2006). This was also noted in works by Aubrey (2001), and Kwak and Anbari (2004).

Poor tool and project selection: Continuous improvement tools or management methodologies can be adopted without being part of a companywide or specific improvement programme. The reasons for selection are often ad-hoc (Samson \& Challis, 2002) and there is a view that some tools may be too simplistic and not appropriate for the project to which they are applied (Bamford \& Greatbanks, 2005).

Poor communication: For any change initiative to be accepted the employees need to be made aware of the reasons for its implementation, how it will be implemented, when and by whom. Poor communication leads to speculation and rumour with employees making up their own reasons for the implementation with most relating this to job losses etc. Even if organisations consider their communication mechanism to be good, thought should be given to ensuring that all employees are given the same clear message, if possible all at the same time. This may involve having communication methods beyond the existing communication processes. Kotter (1995) highlights the significance of communication when he cites that communication is a difficult task stating that 
common pitfalls are for senior executives to communicate during initiation of training but after this no further communications takes place leaving the employees wondering if the methodology was just another fad which has failed. It is not uncommon to find that some companies have little interaction or communication between different parts of the organisation and don't communicate on general business let alone improvement initiatives. They tend to remain in what is termed as 'silos' rarely indulging in cross functional communication. Many publications suggest the importance of 'broadcasting' project information, especially success stories and the need to be an open organisation (Powell, 1995).

Lack of training: Pavnaskar et al (2003) ascertained that failure through misapplications of tools and methodologies tended to occur at an early stage of the development of continuous improvement in the organisation, when there was a lack of understanding and knowledge of the tools and methodologies, due to a lack of training. Continuous improvement tools and management methodologies should be part of a detailed implementation and improvement plan, and to succeed require that a number of critical success factors are met, including a full training plan (McQuater et al., 1995).

This section has highlighted that whilst there is a wide selection of tools and methodologies available there is also a significant possibility of initiatives failing to reach their intended objective due to a number of common and fundamental factors.

\section{Methodology}

This research had the overarching objective of investigating how useful continuous improvement tools and methodologies were as approaches to improving business performance. The specific aims were to identify (i) the level of understanding and use of continuous improvement tools and methodologies within automotive supplier organisations and (ii) the factors which contribute to them failing to achieve the results expected.

The research was undertaken with the cooperation and support of a global automotive OEM who have a manufacturing plant within the UK. The OEM allowed access to their first tier supplier network, provided an introductory letter and data on supplier performance. The method used to collect data was a detailed survey with follow-up telephone interviews with all respondents to provide additional clarity and information. The survey took the form of a self-completion questionnaire completed by Quality Directors, Quality Managers or Continuous Improvement Champions in each organisation, and consisting of questions either asking for a rating on a Likert scale (Easterby-Smith, Thorpe, \& Lowe, 2002) or those asking for qualitative information. The broad topics asked in the survey were related to understanding the use of continuous improvement tools and management methodologies within the supplier base. The survey investigated which continuous improvement tools and management methodologies were being used and their success rates, in addition to associated issues such as awareness, costs, training and management support etc.

\section{Results}

The sample size for the survey was 267 (all the OEM's first tier suppliers) and had a response rate of $60.67 \%$ $(\mathrm{n}=162)$. The breakdown of responses was: $82 \mathrm{UK}$ suppliers $(51 \%)$ and 80 non-UK suppliers $(49 \%)$. Due to the diverse products delivered by component suppliers it was decided to also categorise responses by primary product group supplied to the OEM (Table 1). The product groups selected were:

- Trim components including items such as glazing, internal and external plastics and rubbers, carpets, soft furnishings, etc.

- Chassis components including wheels, tyres, engine components, sub-frames, suspension, brake systems, exhausts etc.

- Electrical components including radios, engine management systems, wiring harnesses, computers, switches, lighting etc.

Table 1. The breakdown of responses by location and product type

\begin{tabular}{lll}
\hline Product Group & UK Suppliers & Non UK Suppliers \\
\hline Trim $(30.8 \%)$ & $30(18.5 \%)$ & $20(12.3 \%)$ \\
Chassis $(50 \%)$ & $43(26.5 \%)$ & $38(23.5 \%)$ \\
Electrical (19.2\%) & $9(5.6 \%)$ & $22(13.6 \%)$ \\
\hline
\end{tabular}

\subsection{Knowledge of Tools and Methodologies}

The data was used to determine the level of understanding of continuous improvement tools and management methodologies by senior personnel within the automotive supplier organisations (Table 2). 
Table 2. The level of understanding of continuous improvement tools and management methodologies

\begin{tabular}{llll}
\hline Location & $\begin{array}{l}\text { Good understanding of } \\
\text { continuous improvement tools }\end{array}$ & $\begin{array}{l}\text { Good understanding of } \\
\text { management methodologies }\end{array}$ & $\begin{array}{l}\text { Considered to have good } \\
\text { overall 'Lean Acumen' }\end{array}$ \\
\hline UK $(\mathrm{n}=82)$ & $\mathrm{n}=24(29.3 \%)$ & $\mathrm{n}=17(20.7 \%)$ & $\mathrm{n}=16(19.5 \%)$ \\
Non-UK $(\mathrm{n}=80)$ & $\mathrm{n}=33(41.25 \%)$ & $\mathrm{n}=24(30 \%)$ & $\mathrm{n}=22(27.5 \%)$ \\
All $(\mathrm{n}=162)$ & $\mathrm{n}=57(35.2 \%)$ & $\mathrm{n}=41(25.3 \%)$ & $\mathrm{n}=38(23.5 \%)$ \\
\hline
\end{tabular}

Reviewing the findings there would appear to be a relatively low understanding of both tools and methodologies. In addition only $23.5 \%$ of respondents were deemed to have a good overall 'lean acumen' and understood the part that tools and methodologies play in continuous improvement implementation.

Respondents were asked to indicate how they had gained their understanding of continuous improvement (Table 3 ). It appears that most had only a superficial level of understanding of continuous improvement tools and management methodologies, with many of them receiving little or no formal training and actually only knowing of them through attending business conferences or through business publications.

Table 3. How knowledge of continuous improvement tools and management methodologies was gained

\begin{tabular}{llll}
\hline & Received awareness training & Received full training & Conference or business publications \\
\hline CI Tools & $\mathrm{n}=47(29.0 \%)$ & $\mathrm{n}=25(15.4 \%)$ & $\mathrm{n}=82(100 \%)$ \\
Management & $\mathrm{n}=62(38.3 \%)$ & $\mathrm{n}=34(21.0 \%)$ & $\mathrm{n}=80(100 \%)$ \\
Methodologies & & &
\end{tabular}

Note: Respondents could specify more than one answer

\subsection{The Use of Continuous Improvement Tools in Automotive Suppliers}

Each supplier was given a list of tools and asked to state if they had used the tools, if they were still using the tools, and how they rated the usefulness of the tool (Figure 1).

\begin{tabular}{|c|c|c|c|c|}
\hline Touls & $\begin{array}{l}\text { Percentage of } \\
\text { suppliers using } \\
\text { the tool }\end{array}$ & $\begin{array}{l}\text { Awerage rating of } \\
\text { suppliers still } \\
\text { using the tool }\end{array}$ & $\begin{array}{c}\text { Awerage rating of } \\
\text { suppliers no } \\
\text { longer using the } \\
\text { tool }\end{array}$ & $\begin{array}{l}\text { Difference in } \\
\text { rating }\end{array}$ \\
\hline FMEA & 65.93 & 3.44 & $\mathrm{~N} / \mathrm{A}$ & $\mathrm{N} / \mathrm{A}$ \\
\hline Pareto & 65.30 & 3.50 & 2.92 & 0.66 \\
\hline Process Capability & 63.74 & 3.56 & 3.38 & 0.19 \\
\hline Cause and Effect & 60.99 & 3.50 & 3.06 & 0.44 \\
\hline Flow Charting & 60.99 & 3.40 & 3.00 & 0.40 \\
\hline Brain Storming & 59.89 & 3.47 & 2.65 & 0.82 \\
\hline $\mathrm{SPC}$ & 55.49 & 3.30 & 2.84 & 0.46 \\
\hline Histagrams & 54.40 & 3.42 & 2.54 & 0.88 \\
\hline Standard Operations & 53.65 & 3.46 & 3.23 & 0.23 \\
\hline Control Charts & 52.75 & 3.41 & 2.70 & 0.71 \\
\hline $5 S$ & 51.10 & 3.46 & 2.79 & 0.67 \\
\hline 5 Why's & 50.55 & 3.41 & 2.92 & 0.49 \\
\hline Kaizen & 45.05 & 3.35 & 2.52 & 0.83 \\
\hline Risk Analysis & 39.56 & 3.40 & 2.57 & 0.83 \\
\hline IIT & 31.32 & 3.29 & 2.67 & 0.63 \\
\hline Gantt Charts & 30.22 & 3.32 & 2.52 & 0.80 \\
\hline Tree Diagram & 21.98 & 3.15 & 2.12 & 1.03 \\
\hline Prioritisation Matrix & 19.78 & 3.28 & 2.71 & 0.57 \\
\hline Run Charts & 19.78 & 3.23 & 2.22 & 1.01 \\
\hline Radar Charts & 19.23 & 2.82 & 2.09 & 0.74 \\
\hline Scatter Diagrams & 19.23 & 2.97 & 1.76 & 1.21 \\
\hline Minitab & 16.48 & 3.55 & 2.38 & 1.17 \\
\hline Balanced Scorecard & 15.93 & 3.29 & 2.90 & 0.39 \\
\hline Story Board & 15.93 & 3.00 & 2.42 & 0.58 \\
\hline Activity Networking & 14.84 & 3.22 & 2.58 & 0.64 \\
\hline Correlation & 13.19 & 3.04 & 2.44 & 0.61 \\
\hline Annova & 10.44 & 3.16 & 2.11 & 1.05 \\
\hline Affinity & 9.34 & 2.82 & 1.92 & 0.90 \\
\hline Kepnar Tregoe & 8.24 & 2.33 & 1.67 & 0.67 \\
\hline Sipoe & 8.24 & 3.39 & 1.80 & 1.52 \\
\hline Stakeholder Analysis & 7.69 & 3.07 & 1.75 & 1.32 \\
\hline Forcefield Analysis & 6.59 & 3.08 & 2.50 & 0.58 \\
\hline \multirow[t]{3}{*}{$\mathrm{RACl}$} & 4.40 & 3.13 & 2.50 & 0.6 .3 \\
\hline & Awerage $=$ & 3.25 & 2.51 & \\
\hline & Std Deviation $=$ & 0.26 & 0.43 & \\
\hline
\end{tabular}

Figure 1. Continuous improvement tools used by the OEM's supplier base

(Note: tool rating relating to the usefulness/ease of use of the tool using Likert Scale of 1 to 5 , where $5=$ very useful to $1=$ of no use.) 
Three key conclusions can be drawn from the analysis of the data collected on the use of continuous improvement tools:

- A very large number of tools are being used that range from the simplistic to the more advanced. In addition, some organisations are using a large number of tools, i.e. all of the 33 tools contained within the list.

- The indicators (average scores and the difference between scores) would support the assumption that tools largely continue to be used where they are perceived to be of value to the organisation. There is no difference between the amount of tools adopted by an organisation and their location, the products they produce and the focus of their company business.

- One of the tools, $5 \mathrm{~S}$, was found to be increasing in its use probably due to the fact that is seen as being the starting point and the foundation for continuous improvement. Unfortunately, during the telephone interviews it became apparent that many of the automotive suppliers are doing little more than housekeeping, rather than using $5 \mathrm{~S}$ in the way intended.

\subsection{The Use of Management Methodologies}

Suppliers were asked in the survey to explain which management methodologies they used, when they were implemented and if applicable when did they stop using them. When considering usage the results indicate that Benchmarking (used by $50 \%$ of respondents) and TQM (used by $42 \%$ of respondents) were the most commonly used with Policy Deployment (used by $29.5 \%$ of respondents) third. 50\% of suppliers indicated that they had implemented Benchmarking; this can be broken down further into distinct groups:

- Group 1: Suppliers compare their performance against other factories in their own company group. 83 suppliers said they performed this level of benchmarking.

- Group 2: Suppliers compare their performance against competitors in their own field. 76 suppliers said they performed this level of benchmarking.

- Group 3: Suppliers compare their performance as discussed in group 1 and 2 above but also to other organisations outside of their own product group or manufacturing areas. 14 suppliers indicated that they performed this level of benchmarking.

There were differences in the amount of methodologies used by each product group with the 'Electrical' suppliers scoring the highest for usage in four out of six methodologies (Table 4). Initially there seemed to be no clear reason why this should be or why BPR is so low at only $9.68 \%$ for Electrical suppliers. However when questioned, the Electrical suppliers indicated that BPR was considered to be out of date as a methodology and had been superseded by Six Sigma and more recently through the resurgence of Policy Deployment.

Table 4. The use of management methodologies (\% of Suppliers)

\begin{tabular}{lcccccc}
\hline Product Group & TQM & Six Sigma & Bench-marking & Change Management & BPR & Policy Deployment \\
\hline Chassis suppliers & 35 & 20 & 50 & 16 & 16 & 23 \\
Electrical Suppliers & 68 & 32 & 58 & 45 & 10 & 48 \\
Trim suppliers & 37 & 33 & 49 & 20 & 16 & 35 \\
\hline Total Percentage & 42 & 26 & 50 & 23 & 14 & 30 \\
\hline
\end{tabular}

During the survey and subsequent telephone interviews the suppliers were asked to explain the year they had adopted each methodology and if applicable the year they believed they stopped using them. The literature had indicated that the use of Six Sigma was on the increase (Harry and Schroeder, 2000) however only 26\% of suppliers said they were currently using Six Sigma. When analysed further the data showed that there was in fact a declining trend where a reducing number of suppliers were choosing to adopt or continue to use the methodology. The data showed that $51.5 \%$ of the suppliers $(\mathrm{n}=85)$ had at some point used Six Sigma with a peak of 65 suppliers using the Methodology in 2001. However there had been a steady decline year upon year since 2001 due to its complex nature, expensive training requirements and that many business issues could be addressed with simpler, faster and more effective tools or methodologies. Reasons given for no longer using TQM or BPR included; a belief that the methodologies were too complex and could only be used by suppliers who wanted to change all areas of their business rather than focused areas; or they was seen as an old methodologies launched in the 1980s. 
The survey showed a decline in BPR, TQM and Six Sigma but when looking at the average time that suppliers used the methodology it was found that there was a difference between each methodology and between locations (Table 5). The table shows that BPR had the shortest life span both in UK (14 months) and Non-UK companies (23 months), followed by Six Sigma and then TQM which was used for the longest period of time. The Non-UK based suppliers were also found to use each of the methodologies for a longer time period than the UK based suppliers. This may suggest that Non-UK based suppliers allow a greater amount of time for planning, implementation and on-going use of the methodologies compared to UK suppliers. During the follow-up telephone interviews all the suppliers were asked to explain why the methodologies were used for the specified period of time and why they were no longer used. It was found that UK suppliers generally rushed in to the implementation with limited planning and a poor supporting structure often resulting in poor sustainability or failure of initiatives. The Non-UK suppliers appeared on average to put a greater emphasis on planning, training and implementation and allowed a greater period of time for the methodology to become embedded. However, surprisingly there was no significant difference in success figures between UK and Non-UK suppliers.

Table 5. The average time methodologies were used by suppliers

\begin{tabular}{lccc}
\hline & TQM & Six Sigma & BPR \\
\hline Average Time (months) used by UK based Suppliers & 32 & 25 & 14 \\
Average Time (months) used by non-UK based suppliers & 54 & 35 & 23 \\
\hline
\end{tabular}

With the exception of Six Sigma the Non-UK based suppliers used each management methodology in greater numbers (Table 6). Six Sigma is known to be the most recent of the methodologies discussed in the survey so a review of the implementation dates for Six Sigma in each supplier was conducted. The results showed that UK suppliers on average implemented Six Sigma 14 months before Non-UK suppliers (the only exceptions were two suppliers from the USA who adopted the methodology before any UK based suppliers this may be due to Six Sigma originating in the USA). The same implementation study for the other methodologies showed in all cases that the UK based suppliers implemented (on average) the methodologies before Non-UK based suppliers.

Table 6. The use of methodologies by location

\begin{tabular}{lcc}
\hline Methodology & $\begin{array}{c}\text { UK Suppliers Using } \\
\text { (\% of all UK suppliers) }\end{array}$ & $\begin{array}{c}\text { Non UK Suppliers Using } \\
\text { (\% of all Non-UK suppliers) }\end{array}$ \\
\hline Six Sigma & $27(33 \%)$ & $16(20 \%)$ \\
Bench Marking & $33(40 \%)$ & $48(60 \%)$ \\
TQM & $22(27 \%)$ & $46(57 \%)$ \\
BPR & $9(11 \%)$ & $14(17 \%)$ \\
Change management & $14(17 \%)$ & $24(30 \%)$ \\
OPD & $17(21 \%)$ & $31(39 \%)$ \\
\hline
\end{tabular}

Management methodologies were implemented in significantly greater numbers in suppliers whose sole business was automotive related. This was not unexpected as in much of the literature the automotive industry is referred to as taking the lead in many continuous improvement initiatives often implementing tools and methodologies a number of years in advance of non-automotive companies. When questioned the suppliers indicated that they felt that there was ever increasing pressure from the automotive OEM's for cost reduction, quality improvement and to use the management methodologies. In the case of suppliers who manufacture for other sectors the automotive OEM would possibly be unable to apply the same pressure. The power of the OEM to influence the suppliers clearly depends upon the percentage of business each supplier has with the relevant OEM.

Three key conclusions that can be drawn from the analysis of the data collected on the use of management methodologies:

- A range of management methodologies were being used within the respondent organisations as may be expected; however, what was not expected was the small amount of organisations using BPR and the relevant decline in Six Sigma usage. In addition, Benchmarking as a management methodology was the most utilised of the methodologies seeing a considerable resurgence in its use in recent years. 
- The number of methodologies an organisation adopted was significantly different amongst UK and Non-UK based organisations, with the latter adopting more. In addition, there was a time lag between the adoption of the methodologies in Non-UK organisations, when compared to UK based organisations.

- Suppliers who manufacture products solely for the automotive industry made greater use of management methodologies possibly due to pressure from the automotive OEMs.

\subsection{The Selection of Tools and Methodologies}

The suppliers were asked a number of questions relating to why continuous improvement tools and management methodologies were actually selected within their organisations. Figure 2 indicates that $69 \%$ of suppliers had selected tools or methodologies in order to help solve problems within the business. These results are similar to the finding of Chapman and Sloan (1999) who found that the main reasons for implementing continuous improvement relate to improved quality and problem solving, cost reduction and increased productivity.

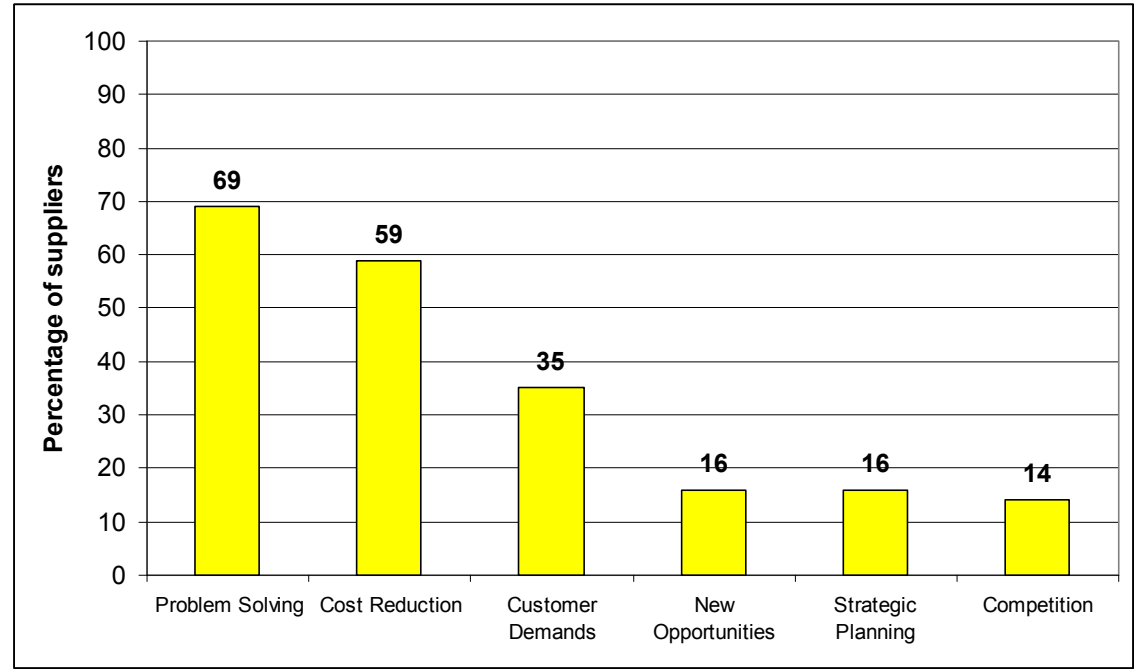

Figure 2. The reasons for selection (Note: suppliers were able to select more than one reason)

During the telephone interviews further clarification was sort as to how the current tools and methodologies being used were selected. In $82 \%$ of suppliers the tools or methodologies were selected with no specific objectives or strategic application for their use being defined before selection. The tools or methodologies were selected, employees trained and then the company required their staff to identify opportunities to apply the tool or methodology. A large number of suppliers train their staff in continuous improvement tools or management methodologies after which staff then try to identify business issues to which apply their new knowledge. The result in most cases was that the companies would then develop a large list of issues that need to be reviewed and addressed. However, in most of the suppliers the resources were limited and it was both impractical and impossible to address all the issues so some level of issue prioritisation had to take place.

The survey found that $42 \%$ of respondents believed that the methods for the selection of tools and methodologies were effective, however over $74 \%$ of respondents indicated that their company had no process for highlighting areas for business improvement. It would appear that these two factors demonstrate a lack of strategic thinking in some organisations which has manifested itself in the situation where tools and methodologies are adopted without a specific and relevant business need being identified.

It was also suggested by some of the respondents that senior managers lacked a detailed understanding of tools or methodologies and this had an effect on their ability to make a sound judgement on the rationale for selection. It was found that where a greater understanding of the tools and methodologies existed it was believed that the success rates were higher, a finding of Herron and Braiden (2004).

\subsection{Application Failure}

The success or failure of the application of continuous improvement tools or management methodologies within an organisation can be judged in terms of how it meets its intended objectives. A good implementation with a problem solved or productivity improvement made, will give the tool or methodology some credibility with the 
users and senior management within the company where as a poor implementation will result in a reluctance to use the tool or methodology for future activities.

The suppliers were asked to indicate what percentage of activities and implementations delivered the required results and were therefore deemed to be successful. The average failure rate for all companies was $27 \%$. In addition $93 \%$ of the suppliers indicated that they had experienced some level of failure although $40 \%$ of these could not quantify the amount of failure within their companies as they did not measure success rates. This is a worrying statistic considering the amount of resources being invested in the implementation of tools and management methodologies.

The research has indicated that although some initiatives were successful, and met the initial project objectives, there was a secondary negative issue forthcoming from the implementation. An example of this would be where the activity had saved the company money, but where there had been a detrimental effect on the service or output the customer received. This was evident in 5 of the 10 worst performing OEM suppliers (as specified by the OEM's supplier development team) who had implemented improvement programmes and had solved some significant problems, yet their quality performance had declined during this period. This was believed to be due to the company focusing its resources on the improvement programmes and taking their focus off their day to day operations.

This issue was investigated further through analysis of the OEM's supplier performance data. One customer measure, the Parts Per Million (PPM) defect ratio for parts delivered to the OEM was compared looking at each companies PPM level before and after the introduction of one methodology Six Sigma. Six Sigma was selected as it is seen as being a methodology that uses a myriad of statistical tools and techniques to fully analyse issues, to establish root cause and to develop robust countermeasures. Many Six Sigma projects are reported to have both a high impact on cost savings and quality within companies implementing it.

The analysis has shown that of the suppliers implementing Six Sigma 44\% of suppliers had improved their quality performance, $19 \%$ had not changed and 37\% had significantly got worse. Several of the suppliers believed that their worsening PPM performance could not be directly related to the Six Sigma implementation, but they did agree that resources were being used to support Six Sigma activities in various business areas often to the detriment of manufacturing areas where resources were already stretched. This raises the issue that any implementation will require either additional resources or a recognised change in focus for existing resources. The PPM levels for suppliers before and after implementation were compared looking at product groups (Figure 3) and no one product group was significantly better or worse in PPM than any other. Electrical and Trim product groups had the greater number of improved suppliers however they also had suppliers who's PPM performance had decreased since the introduction of Six Sigma.

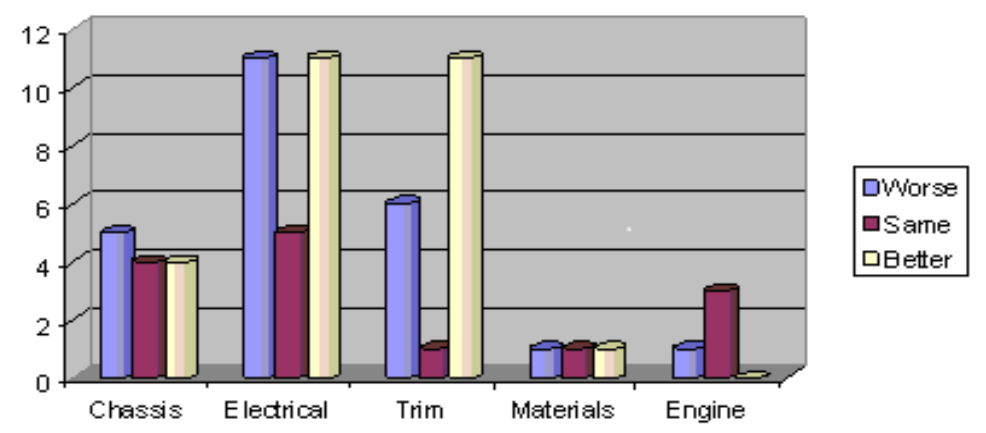

Figure 3. Supplier PPM trend: Post -Six Sigma implementation

\subsection{Reasons for Failure}

The reasons for failure and poor sustainability found in the survey are varied and largely agree with those identified within the literature. Table 7 compares the reasons for failure outlined in the literature to those highlighted and quantified during the survey and telephone interviews. 
Table 7. Reasons for failure

\begin{tabular}{lll}
\hline $\begin{array}{l}\text { Main reasons for failure forthcoming } \\
\text { from the 'literature' }\end{array}$ & $\begin{array}{l}\text { Equivalent reasons for failure } \\
\text { forthcoming from the 'survey' }\end{array}$ & $\begin{array}{l}\text { \% of survey respondents who } \\
\text { stated this reason for failure }\end{array}$ \\
\hline Lack of Resources & Resources & $34 \%$ \\
People and Cultural issues & Culture and commitment & $19 \%$ \\
Poor Implementation and Planning & Poor Project Management & $15 \%$ \\
Poor Management Commitment & Limiting Management Support & $8 \%$ \\
Poor Tool and Project Selection & Poor Project Selection & $6 \%$ \\
& Tool Selection & $8 \%$ \\
Poor Communication & Lack of Communication & $5 \%$ \\
Lack of Training & Lack of Training & $5 \%$ \\
\hline
\end{tabular}

The lack of resources was cited as the reason for failure for $34 \%$ of the respondents. This will now be discussed further. Organisations struggled with resources as their annual budgets were being cut each year and this coupled with the increased pressure from OEM's further increased the pressure on managers to cut costs and reduce budgets. Resources in this context refer to much more than just labour as there were also many issues around budgets and the amount of investment available to support change initiatives.

In addition, $64 \%$ of respondents either agreed or strongly agreed that resources had been a barrier to the success of the implementation with some of the companies stating that project team members were expected to participate in projects whilst still carrying out their normal daily functions. Although labour was an important resource having a suitable budget for training and materials was also considered to be important. For management methodologies, such as Six Sigma, the cost is high and companies invest a considerable amount of time and money in its development. The survey found that companies investing in management methodologies thought that the investment was significant, and the use of management methodologies was considered as a key strategy that will allow them to achieve their long term aims and as such need to be resourced appropriately.
"Going by the amount of money being invested in its deployment with my own organisation I very much doubt Six Sigma will be short term. I think it will be here a long time as many of the tools have already been tried and tested. I think Six Sigma will however develop and change to suit the needs of the users."

Managers were found to release the people they could afford rather than people who would be best to support the project.

\begin{abstract}
"Our problems seem to be getting people together for any period of time to actually do the projects. The people that are put on to the teams are not the people who can make the decisions."
\end{abstract}

The suppliers felt that the introduction of new management methodologies and the cost of consultants go hand in hand. Companies were understandably concerned by the high cost of external support and many feel the consultants have cornered the market and can demand relatively high fees knowing that companies have no choice but to pay up.

\title{
"Consultants have got it made - a license to print money. The irony is that we used the same consultants to train our staff in Six Sigma's that we also used to introduce $T Q M$ and that wasn't very well received throughout the company."
}

$49 \%$ of companies said they had used external consultants whilst introducing continuous improvement tools or management methodologies (56\% Non-UK and 43\% UK). Most consultants were employed to give training, to facilitate initial projects and help with the initial implementation.
"We knew there were going to be considerable costs for training and for consultants as this was the case with our other divisions. However we under estimated the amount of time we needed to employ consultants which was more expense than we had budgeted for."

Resources are an issue and even more so if companies are struggling to be competitive and having to reduce their headcount in order to make cost saving. This further highlights the need to ensure that continuous improvement initiatives are focused on improving areas or issues that will have a significant impact on business performance. 
To do this effectively companies need to be able to highlight the key business issues and match these with the appropriate tools and methodologies.

\section{Discussion}

\subsection{Key Issues Forthcoming from the Research}

The results from the research have highlighted a number of key issues which need to be addressed if real, and sustainable, benefits resulting from the application of continuous tools and management methodologies are to be achieved. The research has indicated an average implementation failure rate of $27 \%$, with a significant number of suppliers unable to quantify the level of failure due to limited outcome measurement occurring. In addition, as a result of the unique access to the OEM supplier performance data, the research has also highlighted the unexpected consequences of implementation, where product quality has suffered as a result of the diverting of focus and resources to large management methodology based implementations such as Six Sigma.

In essence, it would appear that a number of automotive component suppliers are potentially wasting valuable and scarce resources, effort and missing business opportunities in implementing a range of continuous improvement initiatives which are failing to deliver the results expected. A number of related factors would appear to be contributing to this position:

- The relatively low level of understanding of continuous improvement tools and management methodologies amongst senior personnel,

- The relatively low level of adequate training senior personnel receive in the use and application of continuous improvement tools and management methodologies,

- A lack of a strategic approach to the application of tools and methodologies as a result of tools and methodologies being selected before a clear objective or business need has been identified. This can result in two possible areas of potential misalignment, namely:

(i) Tool/Methodology Misalignment: where an inappropriate tool/methodology is applied to solve a particular problem.

(ii) Deployment Misalignment: when a fundamental assessment of a company's performance has not been undertaken to identify and prioritise the business areas which would benefit from improvement. Failure to do this may result in resource being deployed, and improvements being made, in areas which do not improve business performance.

It would therefore appear that a change in approach is required to address these issues if the full potential of continuous improvement initiatives are to be achieved and the return on resource and effort are to be realised in performance improvement in areas that the business requires.

\subsection{Conclusions}

The research has highlighted the need for a more comprehensive and strategic approach to continuous improvement deployment within automotive component suppliers. A new 'self- assessment' based framework is required which provides (i) the means to undertake an assessment of a company's performance which highlights the significant areas for improvement and (ii) provides guidance on suitable continuous improvement tools or management methodologies that may be used to identify and resolve the contributing issues. This framework should initially be used by companies before commencing the first stages of any continuous improvement implementation with the assessment being done at all levels of the organisation to gain a broad understanding of business issues at all levels and across all functions.

\section{References}

Aubrey, C. A. (2001). What is the future of Six Sigma?. Six Sigma Forum Magazine, November, 47-49.

Bamford, D. R., \& Greatbanks, R. W. (2005). The use of quality management tools and techniques: a study of application in everyday situations. International Journal of Quality \& Reliability Management, 22(4), 376-392. http://dx.doi.org/10.1108/02656710510591219.

Bessant, J., Caffyn, S., Gilbert, J., Harding, R., \& Webb, S. (1994). Rediscovering Continuous Improvement. Technovation, 14(1), 17-29. http://dx.doi.org/10.1016/0166-4972(94)90067-1.

Bhuiyan, N., \& Baghel, A. (2005). An overview of continuous improvement: from past to present. Management Decision, 43(5), 761-771. http://dx.doi.org/10.1108/00251740510597761. 
Bunney, H. S., \& Dale, B. G. (1997). The implementation of quality management tools and techniques: a study. The TQM Magazine, 9(3), 183-189. http://dx.doi.org/10.1108/09544789710168966

Chang, R. (1995). Core Threads of Continuous Improvements. Management Development Review, 8(4),14-16.

Chapman, L. R., \& Sloan, T. R. (1999). Large firms versus small firms - do they implement CI the same way? The TQM Magazine, 11(2), 105-110. http://dx.doi.org/10.1108/09544789910370680.

Cooke, E., \& Dale, B. G. (1995). Organizing for Continuous Improvement: an examination. The TQM Magazine, 7(1), 7-13. http://dx.doi.org/10.1108/09544789510076843

Dale, B. G., \& Mc Quater, R. E. (1998). Managing business improvement and quality: implementing key tools and techniques. Blackwell Publishing, Oxford.

Deloitte Touche Tohmatsu. (2004). Supply Chain Management: Automotive industry point of view. Global Manufacturing Industry benchmark Survey 2004.

Dillard, J. F., Ruchala, L., \& Yuthas, K. (2005). Enterprise resource planning systems: a physical manifestation of administrative evil. International Journal of Accounting Informations Systems, 6(2), 107-127. http://dx.doi.org/10.1016/j.accinf.2005.02.001.

Easterby-Smith, M., Thorpe, R., \& Lowe, A. (2002). Management Research: An Introduction (2nd ed.). Sage Publications, London.

Emiliani, M. L., \& Stec, D. J. (2005). Leaders lost in transformation. Leadership and Organisation Development Journal, 26(5), 370-387. http://dx.doi.org/10.1108/01437730510607862.

Goldenson, D., \& Herbsleb, J. (1995). After the Appraisal: A Systematic Survey of Process Improvement, its Benefits, and Factors that Influence Success. Technical Report CMU/SEI-95-TR-009). Pittsburgh: Software Engineering Institute, Carnegie Mellon University. http://www.sei.cmu.edu/library/abstracts/reports/95tr009.cfm

Grunberg, T. (2003).A review of improvement methods in manufacturing operations. Work Study, 52(2), 89-93. http://dx.doi.org/10.1108/00438020310462890.

Grunberg, T. (2007). Performance Improvement - A method to support performance improvement in industrial operations. PhD thesis. Royal Institute of Technology, Sweden.

Harry, M. J., \& Schroeder, R. R. (2000). Six Sigma: The Breakthrough Management Strategy Revolutionizing the World's Top Corporations. Currency, New York.

Herron, C. (2006). A methodology to disseminate lean manufacturing tools into general manufacturing. $\mathrm{PhD}$ thesis. University of Newcastle, UK.

Herron, C., \& Braiden, P. M. (2004). A methodology for developing sustainable quantifiable productivity improvements in manufacturign companies. $13^{\text {th }}$ International Working Seminar for Production Economics, IGLS, Austria $16^{\text {th }}-20^{\text {th }}$ Febuary 2004.

Hurst, K. (2005). Lean Manufacturing Research Report. Retrieved March 2006, from http://www.themanufacturer.com/irr.

Michela, J. L., Jha, S., \& Noori, H. (1996). The dynamics of continuous improvement: aligning organizational attributes and activities for quality and productivity. International Journal of Quality Science, 1(1), 19-47. http://dx.doi.org/10.1108/13598539610117975.

Kotter, J. P. (1995). Leading changes; why transformation efforts fail. Kotter, March-April, 59-67.

Kwak, Y. H., \& Anbari, F. T. (2004). Benefits, obstacles, and future of six sigma approach. Technovation, 26, 708-715. http://dx.doi.org/10.1016/j.technovation.2004.10.003.

McQuater, R. E., Scurr, C. H., Dale, B. G., \& Hillman, P. G. (1995). Using quality tools and techniques successfully. The TQM Magazine, 7(6), 37-42. http://dx.doi.org/10.1108/09544789510103761.

Pavnaskar, S. J., Gershenonson, J. K., \& Jambekar, A. B. (2003). Classification scheme for lean manufacturing tools. International Journal of Production Research, 41(13), 3075-3090. http://dx.doi.org/10.1080/0020754021000049817.

Perry, L. (1995). Effective facilitators - a key element in successful continuous improvement processes. Training for Quality, 3(4) 9-14. http://dx.doi.org/10.1108/09684879510098204. 
Powell, T. C. (1995). TQM as competitive advantage. A review and empirical study. Strategic Management Journal, 16, 15-37.

Samson, D., \& Challis, D. (2002). Patterns of business excellence. Measuring Excellence, 6(2), 15-21. http://dx.doi.org/10.1108/13683040210431428.

SMMT. (2004). Strengthening the supplier chain. Society of Motor Manufacturers and Traders, UK. Retrieved March 2006, from http://www.smmt.co.uk.

SMMT. (2012). Motor Industry Facts. Society of Motor Manufacturers and Traders, UK. Retrieved Oct 2012, from http://www.smmt.co.uk/wp-content/uploads/SMMT_FACTS_2012_WEBv.pdf.

Stelzer, D., \& Mellis, M. (1998). Success factors of organisational change in software process improvement. $\begin{array}{llll}\text { Software } \quad \text { Process: } & \text { Improvementand }\end{array}$ http://dx.doi.org/10.1002/(SICI)1099-1670(199812)

Strebel, P. (1996). Why do employees resist change? Harvard Business Review, May-June, 86-92.

Weller, L. D. (2000). School attendance problems; using the TQM Tools to identify root causes. Journal of Education Administration, 38(1), 64-82. http://dx.doi.org/10.1108/09578230010310984.

Wickens, P. D. (1998). The Ascendant Organisation. Macmillian Press Ltd, London.

Yeh, Y. F. (2003). Implementing a sustainable TQM System: employee focus. The TQM Magazine, 15(4), 257-265. http://dx.doi.org/10.1108/09544780310486164. 